\title{
Correction to: Use of genomic information to exploit genotype-by-environment interactions for body weight of broiler chicken in bio-secure and production environments
}

Thinh T. Chu ${ }^{1,2,3^{*}} \mathbb{C}$, John W. M. Bastiaansen ${ }^{2}$, Peer Berg ${ }^{1,4}$, Hélène Romé ${ }^{1}$, Danye Marois ${ }^{5}$, John Henshall ${ }^{5}$ and Just Jensen ${ }^{1}$

\section{Correction to: Genet Sel Evol (2019) 51:50}

https://doi.org/10.1186/s12711-019-0493-3

After publication of this work [1], we noticed that there was an error: the formula to calculate the standard error of the estimated correlation $\left(\widehat{\rho_{f, r}}\right)$ between $\hat{u}_{f_{i}}$ and $\hat{u}_{r_{i}}$ in Appendix on page 12 was mistyped. The correct formula for calculation of the standard error should be:

$$
S E\left(\widehat{\rho_{f, r}}\right)=\sqrt{\frac{1-{\widehat{\rho_{f, r}}}^{2}}{n-2}} .
$$

\section{Author details}

${ }^{1}$ Center for Quantitative Genetics and Genomics, Department of Molecular Biology and Genetics, Aarhus University, 8830 Tjele, Denmark. ${ }^{2}$ Wageningen University \& Research, Animal Breeding and Genomics, 6709 PG Wageningen The Netherlands. ${ }^{3}$ Faculty of Animal Science, Vietnam National University of Agriculture, Gia Lam, Hanoi, Vietnam. ${ }^{4}$ Department of Animal and Aquacultural Sciences, Norwegian University of Life Sciences, 1432 Ås, Norway.

${ }^{5}$ Cobb-Vantress Inc, Siloam Springs, AR 72761-1030, USA.

Published online: 21 November 2019

\section{Reference}

1. Chu TT, Bastiaansen JWM, Berg P, Rome H, Marois D, Henshall J, Jensen J. Use of genomic information to exploit genotype-by-environment interactions for body weight of broiler chicken in bio-secure and production environments. Genet Sel Evol. 2019;51:50. https://doi.org/10.1186/s1271 1-019-0493-3

\section{Publisher's Note}

Springer Nature remains neutral with regard to jurisdictional claims in published maps and institutional affiliations. 